www.nature.com/pj

\title{
Swelling control in thermo-responsive hydrogels based on 2-(2-methoxyethoxy)ethyl methacrylate by crosslinking and copolymerization with $\mathrm{N}$-isopropylacrylamide
}

\author{
José M García-García, Marta Liras, Isabel Quijada-Garrido, Alberto Gallardo and Rodrigo París \\ Two different strategies were used to modulate the swelling capacity of thermo-responsive hydrogels based on \\ 2-(2-methoxyethoxy)ethyl methacrylate $\left(\mathrm{MEO}_{2} \mathrm{MA}\right)$ in water. In the first approach, several poly $\left(\mathrm{MEO}_{2} \mathrm{MA}\right)$ hydrogels were \\ synthesized using different proportions of a conventional crosslinker, as tetra(ethylene glycol) dimethacrylate and a \\ non-conventional inorganic crosslinker, as polyhedral oligomeric silsesquioxane (POSS) functionalized with eight methacrylic \\ groups (POSS-meth ${ }_{8}$ ). The experiments showed that the equilibrium swelling and the volume transition temperature (VTT) \\ could be tuned by varying the crosslinker degree, regardless of the type of crosslinker. In the second approach, several poly \\ $\left(\mathrm{MEO}_{2} \mathrm{MA}\right.$-co- $\mathrm{N}$-iPAAm) hydrogels were prepared for the very first time, because $\mathrm{N}$-isopropylacrylamide $(\mathrm{N}$-iPAAm) is also \\ a thermo-responsive component that increases the swelling capacity of the hydrogel in water. In addition, the VTT and the \\ glass transition temperature of these new copolymer hydrogels could also be tuned by varying the monomeric composition. \\ Polymer Journal (2011) 43, 887-892; doi:10.1038/pj.2011.83; published online 31 August 2011
}

Keywords: 2-(2-methoxyethoxy)ethyl methacrylate; $\mathrm{N}$-isopropylacrylamide; polyhedral oligomeric silsesquioxane; tetra(ethylene glycol) dimethacrylate; thermo-responsive hydrogels; volume transition temperature

\section{INTRODUCTION}

Thermo-responsive hydrogels undergo relatively large and abrupt volume changes in response to temperature. ${ }^{1-3}$ Among these materials, $N$-isopropylacrylamide-based ( $N$-iPAAm) hydrogels are the most studied $^{4,5}$ because poly( $N$-iPAAm) shows a well-defined lower critical solution temperature in water at around $31-34{ }^{\circ} \mathrm{C},{ }^{6-8}$ which is close to body temperature. Thus, such stimuli-sensitive hydrogels have been intensively studied with respect to drug delivery ${ }^{9,10}$ and other biomedical applications. ${ }^{11-17}$

Recently, hydrogels based on oligo(ethylene glycol) side chains methacrylic monomers, ${ }^{18-22}$ such as 2-(2-methoxyethoxy)ethyl methacrylate $\left(\mathrm{MEO}_{2} \mathrm{MA}\right)$, were highlighted as a successful alternative to poly $(N$-iPAAm)-based hydrogels because of the advantages of a controllable lower critical solution temperature, ${ }^{23,24}$ high biocompatibility/ low cytotoxicity ${ }^{25,26}$ and facile polymerization by both the free radical and the anionic polymerization mechanisms. ${ }^{27}$ The previous investigations on $\mathrm{MEO}_{2} \mathrm{MA}$-based hydrogels were mainly focused on controlling the thermo-responsive behavior for biomedical applications. For instance, they have been synthesized by controlled radical polymerization techniques, such as atom transfer radical polymerization, to create more homogeneous networks. ${ }^{28}$ In other cases, they have been copolymerized with ionic monomers to obtain additional $\mathrm{pH}$ responsiveness. ${ }^{20,22}$
A major issue that remains almost unexplored for this interesting system is the study of modulating its ability of water uptake or the control of its swelling. It is important to remark that, for many real applications such as drug delivery, the swelling capacity of the thermoresponsive hydrogels before their collapse could be as important as the temperature at which the volume transition takes place. Therefore, the main aim of the present work is to provide tools to obtain $\mathrm{MEO}_{2} \mathrm{MA}$ based thermo-responsive systems with a wide range of equilibrium swelling values at a low temperature. To achieve that, two different approaches were investigated. In one approach, a comparative study on the use of crosslinkers, such as a conventional dimethacrylate and a non-conventional inorganic polyhedral oligomeric silsesquioxane (POSS) with eight methacrylic groups (POSS-meth ${ }_{8}$ ), was carried out. It is well known that the crosslinking density and the crosslinker architecture have notorious effects on the mechanical and swelling properties of the hydrogels. ${ }^{29-32}$ In the other approach, bicomponent networks derived from both $\mathrm{N}$-iPAAm and $\mathrm{MEO}_{2} \mathrm{MA}$ were synthesized and analyzed while considering the higher intrinsic swelling capacity of $N$-iPAAm-based systems. In addition, these new poly $\left(\mathrm{MEO}_{2} \mathrm{MA}-\mathrm{co}-\mathrm{N}\right.$-iPAAm) statistical hydrogels, prepared for the first time, were formed by two different thermo-responsive monomers. Therefore, the volume thermal transition depended on the

Instituto de Ciencia y Tecnología de Polímeros, Departamento de Quimica-Fisica, Consejo Superior de Investigaciones Científicas, Madrid, Spain 


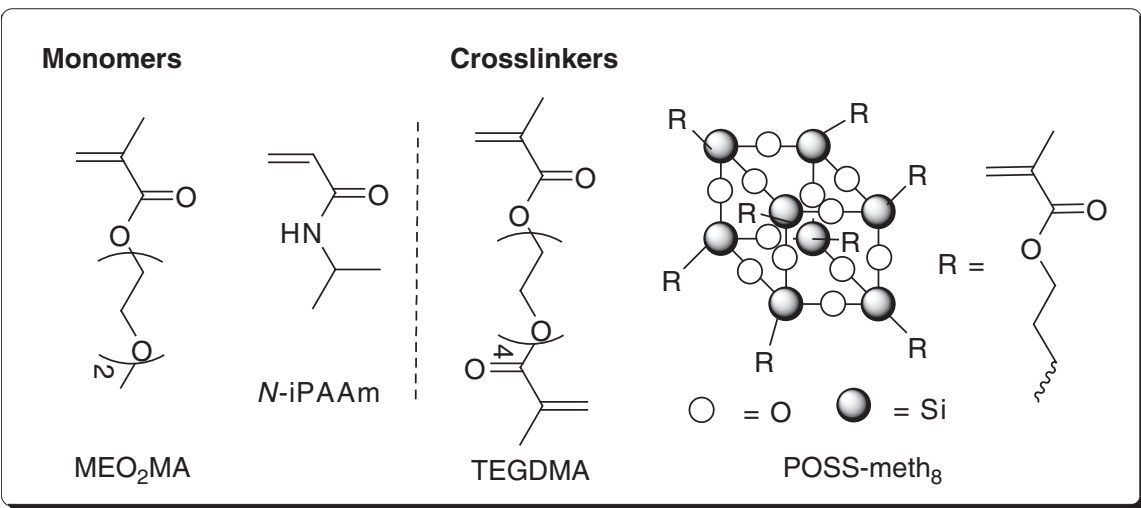

Scheme 1 Structures of the used monomers and crosslinkers.

Table 1 Experimental synthetic conditions and swelling properties of poly $\left(\mathrm{MEO}_{2} \mathrm{MA}\right)$ hydrogels

\begin{tabular}{|c|c|c|c|c|c|c|}
\hline \multirow[b]{2}{*}{ Entry } & \multicolumn{3}{|c|}{ Crosslinker } & \multirow{2}{*}{$\begin{array}{c}Q_{\infty} \text { at } \\
5^{\circ} \mathrm{C}\end{array}$} & \multirow{2}{*}{$\begin{array}{l}V T T^{a} \\
\left({ }^{\circ} C\right)\end{array}$} & \multirow{2}{*}{$\begin{array}{l}A b s_{\max }{ }^{\mathrm{a}} \\
\text { at } 50^{\circ} \mathrm{C}\end{array}$} \\
\hline & Type & $w t \%$ & Mol\% & & & \\
\hline $\mathrm{H} 1$ & TEGDMA & 0.5 & 0.28 & 5.25 & 24.8 & 3.06 \\
\hline $\mathrm{H} 2$ & & 1 & 0.57 & 4.46 & 30.4 & 2.96 \\
\hline H3 & & 2 & 1.15 & 3.17 & 31.9 & 2.36 \\
\hline $\mathrm{H} 4$ & & 5 & 2.91 & 2.29 & 31.8 & 0.81 \\
\hline H5 & & 10 & 5.95 & 1.49 & 33.2 & 0.78 \\
\hline H6 & & 15 & 9.13 & 1.13 & 34.0 & 0.70 \\
\hline $\mathrm{H7}$ & POSS-meth 8 & 0.5 & 0.06 & 5.21 & 26.8 & 3.58 \\
\hline H8 & & 1 & 0.13 & 4.13 & 33.3 & 3.44 \\
\hline $\mathrm{H} 9$ & & 2 & 0.27 & 3.36 & 31.3 & 0.42 \\
\hline $\mathrm{H} 10$ & & 5 & 0.68 & 2.32 & 32.8 & 0.61 \\
\hline $\mathrm{H} 11$ & & 10 & 1.43 & 1.54 & 38.9 & 0.54 \\
\hline $\mathrm{H} 12$ & & 15 & 2.26 & 1.19 & $\mathrm{~b}$ & $\mathrm{~b}$ \\
\hline
\end{tabular}

Abbreviations: POSS-meth ${ }_{8}$, polyhedral oligomeric silsesquioxane functionalized with eight methacrylic groups; $Q_{\infty}$, equilibrium swelling; TEGDMA, tetra(ethylene glycol) dimethacrylate; VTT, volume transition temperature.

Determined by aUV-visible spectrophotometer at $600 \mathrm{~nm}$ in $\mathrm{pH} 7(\mu=0.1 \mathrm{~m})$.

${ }^{\text {b}}$ Non-observable (opaque).

monomeric composition. Using $\mathrm{N}$-iPAAm and ethyl pyrrolidine methacrylate, Elvira et al. ${ }^{33}$ have recently shown that the combination of two different thermo-sensitive units may be a very appropriate way to compositionally adjust some properties (i.e., biocompatibility) of the hydrogels without losing the thermo-responsiveness.

The chemical structures of the monomers and crosslinkers used in this work are collected in Scheme 1.

\section{EXPERIMENTAL PROCEDURE}

\section{Materials}

The monomer $N$-iPAAm (Acros Organics, Morris Plains, NJ, USA, 99\%) was purified by recrystallizing it from an $n$-hexane/toluene mixture $(90 / 10 \mathrm{v} / \mathrm{v})$ and $\mathrm{MEO}_{2} \mathrm{MA}$ (Aldrich, St Louis, MO, USA, 95\%). The monomer was passed through a neutral alumina column to remove the antioxidant inhibitor. The activator $N, N, N^{\prime}, N^{\prime}$-tetramethylethylenediamine (Fluka, Steinheim, Switzerland, $\geqslant 99 \%$ ), the crosslinkers tetra(ethylene glycol) dimethacrylate (TEGDMA, Fluka $\geqslant 90 \%$ ) and the POSS functionalized with eight methacrylic groups (POSS-meth ${ }_{8}$, Hybrid Plastics, Hattiesburg, MS, USA) and the initiator ammonium peroxodisulfate (Fluka $\geqslant 98 \%$ ) were used as received. The water used for all reactions, for the solutions used in the swelling experiments and for hydrogel purification, was Milli.Q from the water purification facility (Millipore MilliU10, Millipore, Billerica, MA, USA). The phosphate buffer solutions were
Table 2 Experimental synthetic conditions and characterization of random distributed poly( $\mathrm{MEO}_{2} \mathrm{MA}-\mathrm{co}-\mathrm{N}$-iPAAm) hydrogels

\begin{tabular}{|c|c|c|c|c|c|c|c|}
\hline Entry & $\mathrm{f}_{\text {MEO2MA }}$ & $\begin{array}{c}{[T E G D M A]_{O}} \\
(w t \%)\end{array}$ & $\mathrm{F}_{M E O 2 M A^{\mathrm{a}}}$ & $\begin{array}{l}\mathrm{T}_{g}^{\mathrm{b}} \\
\left({ }^{\circ} \mathrm{C}\right)\end{array}$ & $\begin{array}{l}\mathrm{T}_{\max }{ }^{\mathrm{C}} \\
(\mathrm{C})\end{array}$ & $\begin{array}{c}\mathrm{Q}_{\infty} \text { at } \\
5^{\circ} \mathrm{C}\end{array}$ & $\begin{array}{l}V T T^{d} \\
\left({ }^{\circ} \mathrm{C}\right)\end{array}$ \\
\hline $\mathrm{H} 1$ & 1.00 & 0.5 & 1 & -31.0 & 254 & 5.2 & 24.8 \\
\hline $\mathrm{RC} 1$ & 0.75 & 0.5 & 0.674 & 0.2 & 343 & 9.3 & 43.0 \\
\hline $\mathrm{RC} 2$ & 0.50 & 0.5 & 0.492 & 12.4 & 390 & 12.5 & 43.5 \\
\hline RC3 & 0.25 & 0.5 & 0.195 & 82.7 & 400 & 16.0 & 47.0 \\
\hline $\mathrm{RC} 4$ & 0.50 & 1.0 & 0.486 & 17.3 & 378 & 8.1 & 45.0 \\
\hline RC5 & 0.50 & 2.0 & 0.468 & 18.1 & 356 & 6.4 & 45.9 \\
\hline
\end{tabular}

Abbreviations: $F_{\mathrm{MEO} 2 \mathrm{MA}}, \mathrm{MEO}_{2} \mathrm{MA}$ fraction in the hydrogel; $Q_{\infty}$, equilibrium swelling; $T_{\mathrm{g}}$, glass transition temperature; $T_{\max }$, temperature at which the weight loss rate was maximum; TEGDMA, tetra(ethylene glycol) dimethacrylate; VTT, volume transition temperature.

Determined by aelemental analysis, bdifferential scanning calorimetry, ${ }^{c}$ thermogravimetric analysis and dUV-visible spectrophotometer at $600 \mathrm{~nm}$ in pH $7(\mu=0.1 \mathrm{~m})$.

prepared using anhydrous sodium dihydrogen phosphate (Fluka $\geqslant 99 \%$ ), disodium hydrogen phosphate (Panreac, Barcelona, Spain, $\geqslant 98 \%$ ) and sodium chloride (Panreac $\geqslant 99.5 \%)$ to keep the ionic strength $(\mu)$ of the solutions constant and under control.

Synthesis of the poly $\left(\mathrm{MEO}_{2} \mathrm{MA}\right)$ hydrogels

Poly $\left(\mathrm{MEO}_{2} \mathrm{MA}\right)$ hydrogels were synthesized by free-radical cross-linking random polymerization. Two different crosslinkers were used, TEGDMA and POSS-meth 8 , using the $\mathrm{MEO}_{2} \mathrm{MA}$ and crosslinker feed ratio described in Table 1. All polymerizations were carried out using a mixture of water/ethanol with a ratio of $1: 1(\mathrm{v} / \mathrm{v})$ and a monomer/solvent ratio of 1:1 $(\mathrm{w} / \mathrm{v})$. The activator $N, N, N^{\prime}, N^{\prime}$-tetramethylethylenediamine and the initiator ammonium peroxydisulfate were used with an initial ratio of $0.5 \mathrm{wt} \%$ of the total monomer amount. The procedure to obtain the sheet-shaped gels is as follows: the mixture solution was cast on a glass plate enclosed by a 1-mm thick rubber framework spacer and sealed off with another glass plate to avoid contact with air during the polymerization process, which lasted for $24 \mathrm{~h}$ at room temperature. Afterward, the gel sheet was removed from the glass plate and uniform disks with a diameter of $6 \mathrm{~mm}$ were punched out of the gel sheet using a stainless steel cork borer. Then, the disks were immersed in freshwater for at least 3 days to remove the unreacted chemicals. During this time, the water was replaced several times. After the immersion process, the hydrogels were dried at room temperature until they achieved constant weight.

\section{Synthesis of randomly distributed poly( $\mathrm{MEO}_{2} \mathrm{MA}-\mathrm{co}-\mathrm{N}$-iPAAm)} hydrogels

The poly $\left(\mathrm{MEO}_{2} \mathrm{MA}-\mathrm{co}-\mathrm{N}\right.$-iPAAm) hydrogels were synthesized by free-radical crosslinking random polymerization using $\mathrm{MEO}_{2} \mathrm{MA}$ and $\mathrm{N}$-iPAAm with the feed ratios given in Table 2. Polymerizations were carried out using a monomer concentration of $1 \mathrm{~g} \mathrm{ml}^{-1}$ with a water/ethanol $(1: 1 \mathrm{v} / \mathrm{v})$ mixture as the solvent in all cases. The activator $N, N, N^{\prime}, N^{\prime}$-tetramethylethylenediamine and the 
initiator ammonium peroxydisulfate were used with an initial weight ratio of $0.5 \mathrm{wt} \%$ with respect to the amount of total monomers, and TEGDMA was the crosslinker used. The procedures to obtain the sheet-shaped gels and the method used to purify them were the same as those previously outlined for poly $\left(\mathrm{MEO}_{2} \mathrm{MA}\right)$ hydrogels.

\section{Characterization}

Fourier transform infrared spectra with attenuated total reflectance (FTIRATR) were recorded on a PerkinElmer Spectrum One spectrophotometer (PerkinElmer, Waltham, MA, USA) with a resolution of $4 \mathrm{~cm}^{-1}$. The thermal stability was determined from thermogravimetric analysis (TGA) at $10{ }^{\circ} \mathrm{Cmin}^{-1}$ under $20 \mathrm{ml} \mathrm{min}^{-1}$ of dry nitrogen flow with a TA TGAQ500 thermogravimetric analyzer (TA Instruments, New Castle, DE, USA). The temperature at which the weight loss rate was maximum $\left(T_{\max }\right)$ was determined from the peak maximum of the first derivative of the weight loss curve. The glass transition temperatures $\left(T_{\mathrm{g}}\right)$ were measured by differential scanning calorimetry (DSC) using a TA DSC Q100 calorimeter connected to a cooling system to work at low temperatures. The samples were scanned from -75 to $150^{\circ} \mathrm{C}$ at a rate of $20^{\circ} \mathrm{C} \mathrm{min}^{-1}$ under $20 \mathrm{ml} \mathrm{min}^{-1}$ of dry nitrogen flow. The $T_{\mathrm{g}}$ values were determined as previously described during the second heating cycle. ${ }^{34}$ Scanning electron microscopy of gold-coated samples was performed on a Philips XL30 microscope (Philips, Eindhoven, the Netherlands) at ambient temperature. The scanning electron micrographs were taken from the newly exposed surface of the samples that fractured immediately after they were introduced in liquid nitrogen. Volume transition temperatures (VTT) of the hydrogels were estimated from the optical transmittance measurements at $600 \mathrm{~nm}$ that were plotted as a function of the temperature of the swollen hydrogels. The transmittance measurements were performed by taking advantage of the decrease in transparency that occurs because of the collapsed polymer. The analysis was made using a Cary 3 BIO-Varian UV-visible spectrophotometer (Agilent Technologies, New Castle, CA, USA). The temperature of the hydrogels was raised from 10 to $80^{\circ} \mathrm{C}$ at a rate of $1{ }^{\circ} \mathrm{C} \mathrm{min}-1$. The VTT was defined as the temperature at the inflection point of the absorbance versus temperature curve. The chemical composition of the comonomeric hydrogels was estimated by organic elemental analysis in a Heraeus CHN-O Rapid Analyzer (Heraeus, Barcelona, Spain). Equilibrium swelling was determined gravimetrically in the following manner: dried hydrogel disks were placed in phosphate buffer solutions or distilled water to swell at different temperatures for $24 \mathrm{~h}$. Then, samples were removed, wiped superficially with a blotting paper and weighed. The equilibrium swelling $\left(Q_{\infty}\right)$ was calculated in grams of water per grams of dry gel using the following expression:

$$
Q_{\infty}=\left(m_{\infty}-m_{0}\right) / m_{0}=W_{\infty} / m_{0}
$$

where $m_{\infty}$ is the weight of the swollen gel at equilibrium, $m_{0}$ is the weight of the dry polymer gel and $W_{\infty}$ is the weight of the solvent uptake at equilibrium.

\section{RESULTS AND DISCUSSION}

Effect of crosslinking on the swelling properties of poly $\left(\mathrm{MEO}_{2} \mathrm{MA}\right)$ hydrogels

Several poly $\left(\mathrm{MEO}_{2} \mathrm{MA}\right)$ hydrogels were successfully synthesized using two different crosslinkers (TEGDMA and POSS-meth ${ }_{8}$ ) with the percentages shown in Table 1. In addition to the percentages of the crosslinkers, the synthesis conditions and the main results of the swelling properties of the hydrogels are also collected in this table. The chemical composition of the hydrogels was corroborated by FTIR-ATR (Supplementary Figure 1-SI), and the formation of a crosslinked structure was evidenced by the fact that the hydrogels did not dissolve in water but swelled. The scanning electron microscopy image shown in Supplementary Figure 2-SI indicated that the POSS-crosslinker dispersed well and did not form large aggregates, as expected. ${ }^{35}$ In addition, no significant variation in the thermal properties was detected by DSC and TGA because the $T_{\mathrm{g}}$ remained at approximately $-33^{\circ} \mathrm{C}$ and a unique thermal decomposition in nitrogen was observed at $250-270{ }^{\circ} \mathrm{C}$.

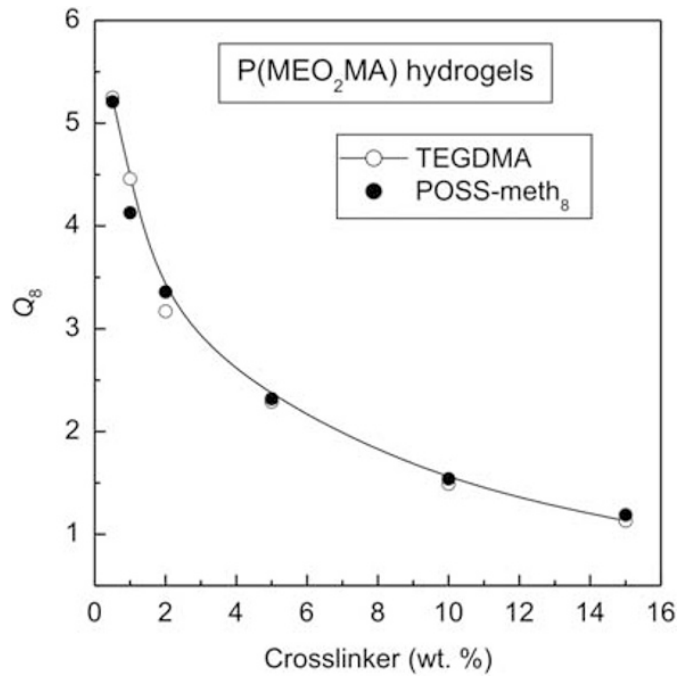

Figure 1 Equilibrium swelling for poly $\left(\mathrm{MEO}_{2} \mathrm{MA}\right)$ hydrogels at $5^{\circ} \mathrm{C}$ in aqueous solutions as a function of the crosslinker type and amount.

The $Q_{\infty}$ values of the hydrogels in water at $5{ }^{\circ} \mathrm{C}$ as a function of the amount and type of crosslinker are shown in Figure 1. As expected, increasing the crosslinker amount reduced the capacity of the hydrogels to incorporate water in their network structure. Their highly crosslinked structure resulted in a marked decrease in the swelling ratio due to the reduction in the free volume within the hydrogel network. ${ }^{36,37}$ Interestingly, the equilibrium swelling values did not seem to depend on the type of crosslinker used. Thus, the experimental data on equilibrium swelling exponentially decayed as the percentage of crosslinker increased in the experimental range in both cases. This behavior could be explained by taking the molar mass of the different crosslinkers into account. Thus, the molar percentages of the crosslinkers in each sample are included in Table 1. The higher number of methacrylic double bonds in POSS-meth ${ }_{8}$ caused the observed reduction on the equilibrium swelling. Furthermore, it is

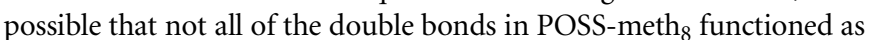
crosslinker points because of steric effects according to Sastre et al. ${ }^{35}$

One of the most interesting features of the $\mathrm{MEO}_{2} \mathrm{MA}$-based hydrogels is their thermo-responsiveness. ${ }^{19,20,22,28}$ Thus, the waterswelling capacity of the samples was evaluated as a function of temperature. The experimental results are collected in Figure 2. The hydrogels were thermo-responsive materials and showed much higher equilibrium swelling values at lower temperatures. In fact, all samples were in the collapsed state at body temperature. The figure showed that equilibrium swelling at each temperature clearly depended on the total crosslinker amount used. In addition, the collapse temperature seemed to increase slightly as the crosslinker amount increased. These results are related to the fact that thermal transition is a function of inter macromolecular interactions (hydrophobic/hydrophilic balance). On the other hand, equilibrium swelling depends on the monomeric composition, which is almost the same for all samples, and on the crosslinking degree, which is the parameter that is being studied to control the swelling capacity in water at low temperature.

In previous investigations, ${ }^{19,20,22}$ it was shown that the VTT of the $\mathrm{MEO}_{2}$ MA-based hydrogels occurred with a very fast change in the sample transparency. Thus, these hydrogels were completely transparent at low temperatures but became opaque above the transition temperature. Other than the possible applications of this phenomenon (i.e., in smart windows), this fact allowed the VTT of 


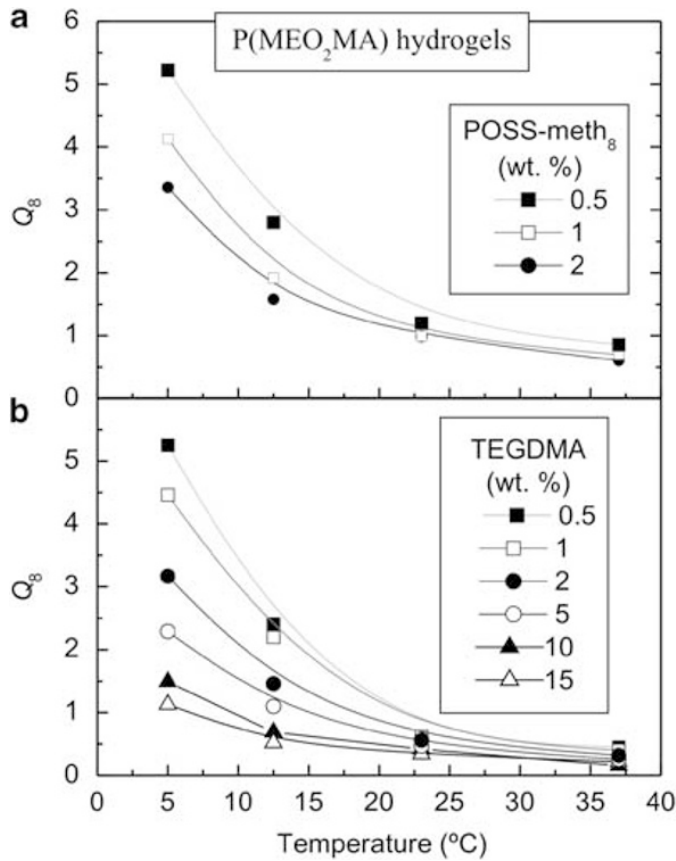

Figure 2 Equilibrium swelling versus temperature for poly $\left(\mathrm{MEO}_{2} \mathrm{MA}\right)$ hydrogels synthesized using (a) POSS-meth 8 and (b) tetra(ethylene glycol) dimethacrylate (TEGDMA) as crosslinkers.

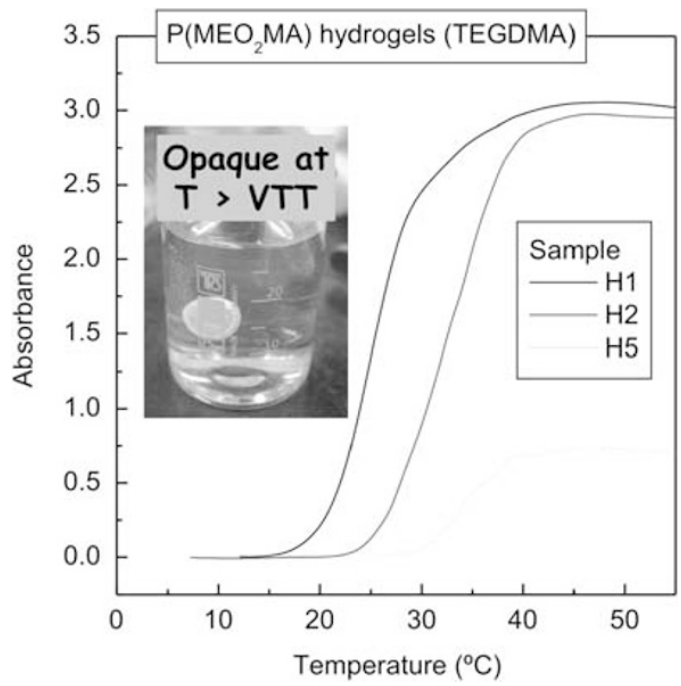

Figure 3 Absorbance at $600 \mathrm{~nm}$ versus temperature of swollen poly $\left(\mathrm{MEO}_{2} \mathrm{MA}\right.$ ) hydrogels (samples $\mathrm{H} 1, \mathrm{H} 2$ and $\mathrm{H} 5$ ). Photograph of sample $\mathrm{H} 5$ taken in an aqueous solution at temperature above volume transition temperature (VTT) is included. A full color version of this figure is available at Polymer Journal online.

these hydrogels to be estimated by the cloud-point method. In this method, the absorbance at $600 \mathrm{~nm}$ is measured through the swollen specimens as a function of temperature. As an example, Figure 3 shows the absorbance versus temperature curves for samples $\mathrm{H} 1, \mathrm{H} 2$ and $\mathrm{H} 5$ because no significant discrepancies were observed in these samples as the crosslinker type was changed. The experimental VTT values calculated from these curves are collected in Table 1 for all samples. According to the experimental data, the VTT clearly depended on the crosslinker amount, which became higher as the percentage of the crosslinker in the feed increased. This was because

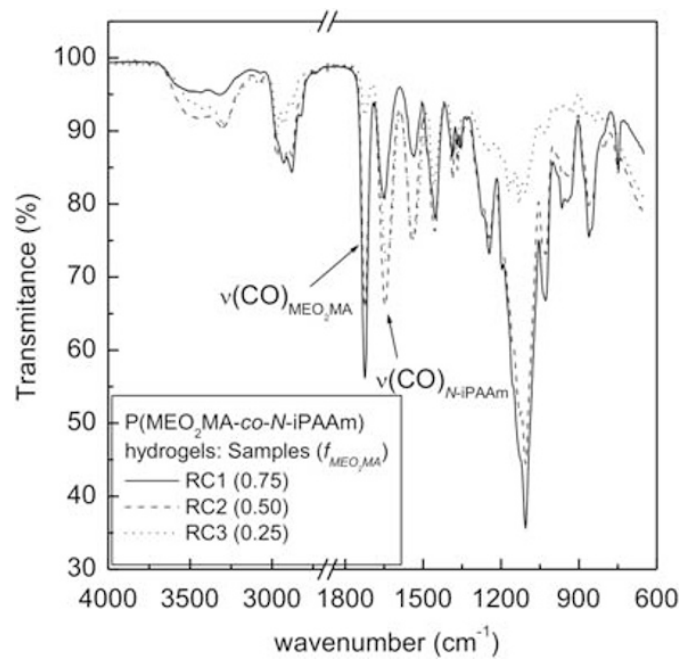

Figure 4 FTIR-ATR spectra of poly( $\left(\mathrm{MEO}_{2} \mathrm{MA}\right)$-co- $N$-iPAAm) hydrogels with different monomer compositions (samples RC1, RC2 and RC3). A full color version of this figure is available at Polymer Journal online.

the intermolecular interactions needed for the polymer to collapse were more restricted. Another interesting result was that the absorbance in the collapse state, which is related to the opacity degree, was also a function of the crosslinker amount. Thus, the maximum absorbance value after the VTT $\left(A b s_{\max }\right)$ decreased with increasing crosslinking degree. Again, this fact could be attributed to the decreased mobility of the crosslinked network that had less interaction between the chains after the collapse.

\section{Swelling and thermo-responsive properties of poly( $\mathrm{MEO}_{2} \mathrm{MA}-\mathrm{co}-\mathrm{N}$-iPAAm) hydrogels}

Several randomly distributed poly $\left(\mathrm{MEO}_{2} \mathrm{MA}-\mathrm{co}-\mathrm{N}\right.$-iPAAm) copolymer hydrogels were synthesized using TEGDMA as the crosslinker to evaluate the effect of introducing a second thermo-sensitive comonomer with a high swelling capacity. The experimental conditions for the synthesis along with the thermal and swelling properties of these copolymeric hydrogels are shown in Table 2. Because only $N$-iPAAm incorporated nitrogen in its structure, the $\mathrm{MEO}_{2} \mathrm{MA}$ fraction in the hydrogel $\left(\mathrm{F}_{\mathrm{MEO} 2 \mathrm{MA}}\right)$ could be easily determined from elemental analysis. The experimental compositions were quite similar to those employed in the feed $\left(\mathrm{f}_{\mathrm{MEO} 2 \mathrm{MA}}\right)$. Moreover, the monomeric composition could also be qualitatively estimated from the FTIR-ATR analysis. The intensity ratio between the stretching band of the carbonyl group of $\mathrm{MEO}_{2} \mathrm{MA}\left(1724 \mathrm{~cm}^{-1}\right)$ and the carbonyl group (amide) of $N$-iPAAm $\left(1646 \mathrm{~cm}^{-1}\right)$ clearly depended on the initial composition ratio. This fact is reflected in the spectra shown in Figure 4.

The thermal properties of these hydrogels were also analyzed by DSC and TGA. The $T_{\mathrm{g}}$ values, estimated by DSC and collected in Table 2, clearly depended on the composition and increased linearly from the $T_{\mathrm{g}}$ of the poly $\left(\mathrm{MEO}_{2} \mathrm{MA}\right)$ hydrogel $\left(-33^{\circ} \mathrm{C}\right)$ to the $T_{\mathrm{g}}$ of the poly $\left(N\right.$-iPAAm) hydrogel $\left(131^{\circ} \mathrm{C}\right)^{38}$ (Supplementary Figure $\left.3-\mathrm{SI}\right)$. It is well known that one of the main limitations of using poly( $N$-iPAAm)based hydrogels is that they are very brittle in the dry state, which is a consequence of their high glass transition temperature. However, in the present study, we showed that for equimolecular compositions or enriched $\mathrm{MEO}_{2} \mathrm{MA}$ compositions, thermo-responsive hydrogels with $T_{\mathrm{g}}$ values lower than room temperature were obtained; this can be very interesting for further applications. The study of the thermal properties was completed with TGA analysis (Supplementary 


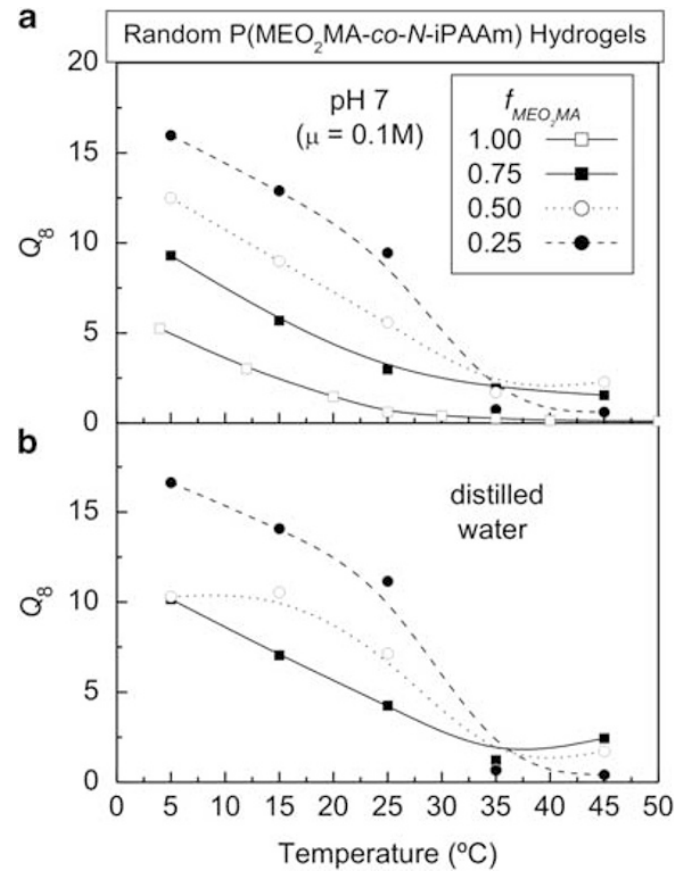

Figure 5 Equilibrium swelling of random poly( $\mathrm{MEO}_{2} \mathrm{MA}-\mathrm{Co}-\mathrm{N}$-iPAAm) hydrogels as a function of temperature and monomeric composition (a) at $\mathrm{pH}=7$ and (b) in deionized water.

Figure 4-SI). It could be observed again that thermal degradation took place in a unique step for all samples. The values of $T_{\max }$ are collected in Table 2. As a consequence of the higher thermal stability of $N$ iPAAm, the maximum temperature of degradation increased when the $N$-iPAAm percentage in the hydrogels increased.

Both poly $(N$-iPPAm $)$ and poly $\left(\mathrm{MEO}_{2} \mathrm{MA}\right)$ are thermo-responsive materials that collapse at 32 and $26^{\circ} \mathrm{C}$, respectively. ${ }^{39}$ Therefore, the synthesized copolymeric hydrogels also present this property. Figure 5 shows the evolution of their equilibrium swelling at several temperatures, and the swelling decreased with increasing temperature. Moreover, the equilibrium swelling at $5{ }^{\circ} \mathrm{C}$ clearly depended on the monomeric composition. As we hypothesized, the monomer $\mathrm{N}$-iPPAm is more hydrophilic than $\mathrm{MEO}_{2} \mathrm{MA}$ and, as a result, hydrogels enriched with $N$-iPPAm had higher experimentally measured $Q_{\infty}$ values than those enriched with poly $\left(\mathrm{MEO}_{2} \mathrm{MA}\right)$. In addition, it is interesting to note that the monomeric composition also affected the thermo-responsiveness. Thus, increasing the $\mathrm{MEO}_{2} \mathrm{MA}$ composition will decrease the transition temperature. In summary, the equilibrium swelling and thermal transition temperature could be easily tuned by varying the monomeric feed composition in these poly $\left(\mathrm{MEO}_{2} \mathrm{MA}-\mathrm{co}-\mathrm{N}\right.$-iPAAm) hydrogels.

Another interesting observation is that the VTTs depended on the type of aqueous solution. Thus, the VTT values of the hydrogels in deionized water (Figure $5 \mathrm{~b}$ ) were higher than the VTT values in water at $\mathrm{pH} 7(\mu=0.1 \mathrm{~m})$. This difference was attributed to the effect of the ionic strength because the hydrogel with a higher ionic strength will have a lower collapse temperature. ${ }^{20}$

Apart from the compositional effect and in consonance with the previous study on the poly $\left(\mathrm{MEO}_{2} \mathrm{MA}\right)$ hydrogels, the crosslinker amount was another experimental variable that was modified to change the swelling capacity of this kind of copolymeric network. Supplementary Figure 5-SI shows the swelling capacity of the poly $\left(\mathrm{MEO}_{2} \mathrm{MA}-\mathrm{co}-\mathrm{N}\right.$-iPAAm) hydrogels with equimolecular monomeric feed ratio. As expected, the hydrogel with a higher crosslinker amount in the feed had a lower swelling capacity in water. Therefore, the equilibrium swelling at low temperatures could be easily tuned by combining the two variables in this study: the crosslinker amount and the comonomer composition.

The VTT values (Table 2) were estimated from cloud-point measurements in the same manner as those of the poly $\left(\mathrm{MEO}_{2} \mathrm{MA}\right)$ hydrogels. The VTT increased with the degree of crosslinking of the hydrogels. Most interestingly, the VTTs were observed to occur at higher temperatures than those of the homopolymers; therefore, the thermo-responsiveness did not follow the additivity rules. We believe that an anti-synergic effect took place. The presence of a randomly distributed comonomer reduced the interaction among the other comonomeric units, forcing the transition to take place at higher temperatures. This explanation is in agreement with previous results obtained with the poly $\left(\mathrm{MEO}_{2} \mathrm{MA}\right) / \operatorname{poly}(\mathrm{N}$-iPAAm $)$ conetworks,${ }^{40}$ in which the VTT values were close to those of the poly $(N$-iPAAm) hydrogels.

\section{Conclusion}

The swelling and optical properties of thermo-responsive $\mathrm{MEO}_{2} \mathrm{MA}$ based hydrogels in aqueous solutions were studied as a function of the crosslinker amount and crosslinker type. These properties could be easily tuned, which could be a very important feature for biomedical applications. In addition, poly $\left(\mathrm{MEO}_{2} \mathrm{MA}-\mathrm{co}-\mathrm{N}\right.$-iPAAm) hydrogels were prepared to evaluate their swelling properties in water because $N$-iPAAm was also a thermo-responsive monomer that showed higher hydrophilic character at low temperatures. Their glass transition temperatures and equilibrium swelling values increased with the $\mathrm{N}$-iPAAm proportion. Moreover, a high increment on the VTT was observed, which could be due to an anti-synergic effect between both thermo-responsive monomers. The poly( $\mathrm{MEO}_{2} \mathrm{MA}-\mathrm{co}-\mathrm{N}$-iPAAm) hydrogels were demonstrated to combine the properties of both comonomers, such as the thermo-responsive behavior, the swelling capacity and the glass transition temperature. Furthermore, these properties could be regulated by varying the monomeric composition.

\section{ACKNOWLEDGEMENTS}

We are grateful for the financial support of the Ministerio de Ciencia e Innovación through the Projects CTQ 2008-03229 and MAT 2010-20001. RP thanks the Ministerio de Ciencia e Innovación for the Juan de la Cierva contract. ML and JG thank the CSIC for the JAE-Doc and the JAE-Predoc contract, respectively.

1 Hoffman, A. S. Hydrogels for biomedical applications. Adv. Drug Deliver. Rev. 54, 3-12 (2002).

2 Jeong, B., Kim, S. W. \& Bae, Y. H. Thermosensitive sol-gel reversible hydrogels. Adv. Drug Deliver. Rev. 54, 37-51 (2002).

3 Imran, A. B., Seki, T. \& Takeoka, Y. Recent advances in hydrogels in terms of fast stimuli responsiveness and superior mechanical performance. Polym. J. 42, 839-851 (2010).

4 Yoshida, R. Development of self-oscillating polymers and gels with autonomous function. Polym. J. 42, 777-789 (2010)

5 Tanaka, T. Collapse of gels and the critical endpoint. Phys. Rev. Lett. 40, 820-823 (1978).

6 Kawaguchi, T., Kojima, Y., Osa, M. \& Yoshizaki, T. Cloud points in aqueous poly (N-isopropylacrylamide) solutions. Polym. J. 40, 455-459 (2008).

7 Peppas, N. A. Hydrogels. in Biomaterials Science: An Introduction to Materials in Medicine (eds Ratner, B. D., Hoffman, A. S., Schoen, F. J. \& Lemons, J. E.) 2nd edn, 100-107 (Academic Press, New York, NY, 2004).

8 Sayil, C. \& Okay, O. The effect of preparation temperature on the swelling behavior of poly(N-isopropylacrylamide) gels. Polym. Bull. 45, 175-182 (2000).

9 Gutowska, A., Bae, Y. H., Feijen, J. \& Kim, S. W. Heparin release from thermosensitive hydrogels. J. Control Release 22, 95-104 (1992). 
10 Sershen, S. R., Westcott, S. L., Halas, N. J. \& West, J. L. Temperature-sensitive polymer-nanoshell composites for photothermally modulated drug delivery. J. Biomed. Mater. Res. 51, 293-298 (2000).

11 Ali, M., Horikawa, S., Venkatesh, S., Saha, J., Hong, J. W. \& Byrne, M. E. Zero-order therapeutic release from imprinted hydrogel contact lenses within in vitro physiological ocular tear flow. J. Control Release 124, 154-162 (2007).

12 Stile, R. A. \& Healy, K. E. Poly(N-isopropylacrylamide)-based semi-interpenetrating polymer networks for tissue engineering applications. 1. Effects of linear poly (acrylic acid) chains on phase behavior. Biomacromolecules 3, 591-600 (2002).

13 Iveković, D., Milardović, S. \& Grabarić, B. S. Palladium hexacyanoferrate hydrogel as a novel and simple enzyme immobilization matrix for amperometric biosensors. Biosens. Bioelectron. 20, 871-877 (2004).

14 Takahara, J., Takayama, K., Isowa, K. \& Nagai, T. Multi-objective simultaneous optimization based on artificial neural network in a ketoprofen hydrogel formula containing O-ethyl menthol as a percutaneous absorption enhancer. Int. J. Pharm. 158, 203-210 (1997).

15 Jiang, H., Campbell, G., Boughner, D., Wan, W. K. \& Quantz, M. Design and manufacture of a polyvinyl alcohol (PVA) cryogel tri-leaflet heart valve prosthesis. Med. Eng. Phys. 26, 269-277 (2004).

16 Mao, L., Hu, Y., Piao, Y., Chen, X., Xian, W. \& Piao, D. Structure and character of artificial muscle model constructed from fibrous hydrogel. Curr. Appl. Phys. 5, 426-428 (2005).

17 Pérez, P., Gallardo, A., Corrigan, O. I. \& Román, J. S. Thermosensitivity of $\mathrm{N}$-isopropylacrylamide hydrogels cross-linked with degradable cross-linker. J. Biomat. Sci.Polym. E. 19, 769-783 (2008).

18 París, R., Barrales-Rienda, J. M. \& Quijada-Garrido, I. Dynamic swelling of hydrogels based on random terpolymers of $\mathrm{N}$-isopropylacrylamide, methacrylic acid and poly(ethylene glycol) macromonomer. Polymer 50, 2065-2074 (2009).

19 París, R. \& Quijada-Garrido, I. Swelling behaviour of thermo-sensitive hydrogels based on oligo(ethylene glycol) methacrylates. Eur. Polym. J. 45, 3418-3425 (2009).

20 París, R. \& Quijada-Garrido, I. Temperature- and pH-responsive behaviour of poly (2-(2-methoxyethoxy)ethyl methacrylate-co-N,N-dimethylaminoethyl methacrylate) hydrogels. Eur. Polym. J. 46, 2156-2163 (2010).

21 Quijada-Garrido, I., Prior-Cabanillas, A., Paris, R., Frutos, G. \& Barrales-Rienda, J. M. Water transport properties of pH-responsive hydrogels based on poly(methacrylic acid) with polyether side chains by magnetic resonance imaging. Macromol. Chem. Phys. 210, 520-530 (2009).

22 París, R., García, J. \& Quijada-Garrido, I. Thermo- and pH-sensitive hydrogels based on 2-(2-methoxyethoxy)ethyl methacrylate and methacrylic acid. Polym. Int. 60, 178-185 (2011).

23 Lutz, J. F. \& Hoth, A. Preparation of ideal PEG analogues with a tunable thermosensitivity by controlled radical copolymerization of 2-(2-methoxyethoxy)ethyl methacrylate and oligo(ethylene glycol) methacrylate. Macromolecules 39, 893-896 (2006).

24 Dong, H. \& Matyjaszewski, K. Thermally responsive P(M(EO)2MA-co-OEOMA) copolymers via AGET ATRP in miniemulsion. Macromolecules 43, 4623-4628 (2010).

25 Lutz, J. F., Andrieu, J., Üzgün, S., Rudolph, C. \& Agarwal, S. Biocompatible, thermoresponsive, and biodegradable: simple preparation of 'All-in-one' biorelevant polymers. Macromolecules 40, 8540-8543 (2007).

26 Lutz, J. F., Stiller, S., Hoth, A., Kaufner, L., Pison, U. \& Cartier, R. One-pot synthesis of PEGylated ultrasmall iron-oxide nanoparticles and their in vivo evaluation as magnetic resonance imaging contrast agents. Biomacromolecules 7, 3132-3138 (2006).
27 Ishizone, T., Seki, A., Hagiwara, M., Han, S., Yokoyama, H., Oyane, A., Deffieux, A. \& Carlotti, S. Anionic polymerizations of oligo(ethylene glycol) alkyl ether methacrylates: effect of side chain length and $\omega$-alkyl group of side chain on cloud point in water. Macromolecules 41, 2963-2967 (2008).

28 Badi, N. \& Lutz, J. F. PEG-based thermogels: applicability in physiological media. J. Control Release 140, 224-229 (2009).

29 Kabiri, K., Omidian, H., Hashemi, S. A. \& Zohuriaan-Mehr, M. J. Synthesis of fast-swelling superabsorbent hydrogels: effect of crosslinker type and concentration on porosity and absorption rate. Eur. Polym. J. 39, 1341-1348 (2003).

30 Caykara, T. \& Turan, E. Effect of the amount and type of the crosslinker on the swelling behavior of temperature-sensitive poly(N-tert-butylacrylamide-co-acrylamide) hydrogels. Colloid Polym. Sci. 284, 1038-1048 (2006).

31 Atta, A. M. \& Abdel-Azim, A. A. A. Effect of crosslinker functionality on swelling and network parameters of copolymeric hydrogels. Polym. Advan. Technol. 9, 340-348 (1998).

32 Aouada, F. A., Chiou, B. S., Orts, W. J. \& Mattoso, L. H. C. Physicochemical morphological properties of poly(acrylamide) methylcellulose hydrogels: effects of monomer, crosslinker and polysaccharide compositions. Polym. Eng. Sci. 49, 2467-2474 (2009).

33 Nash, M. E., Velasco, D., Gomez, J., Gorelov, A., Elezov, D., Gallardo, A., Rochev, Y. \& Elvira, C. Synthesis and characterization of a novel thermoresponsive copolymer series and their application in cell and cell sheet regeneration. J. Biomater. Sci. Polym. Ed. (submitted).

34 París, R. \& De La Fuente, J. L. Glass transition temperature of allyl methacrylate-nbutyl acrylate gradient copolymers in dependence on chemical composition and molecular weight. J. Polym. Sci. Pol. Phys. 45, 1845-1855 (2007).

35 Sastre, R., Martín, V., Garrido, L., Chiara, J. L., Trastoy, B., García, O., Costela, A. \& Moreno, I. G. Dye-doped polyhedral oligomeric silsesquioxane (POSS)-modified polymeric matrices for highly efficient and photostable solid-state lasers. Adv. Funct. Mater. 19, 3307-3316 (2009).

36 Mahdavinia, G. R., Pourjavadi, A., Hosseinzadeh, H. \& Zohuriaan, M. J. Modified chitosan 4. Superabsorbent hydrogels from poly(acrylic acid-co-acrylamide) grafted chitosan with salt- and pH-responsiveness properties. Eur. Polym. J. 40, 1399-1407 (2004).

37 Rasool, N., Yasin, T., Heng, J. Y. Y. \& Akhter, Z. Synthesis and characterization of novel $\mathrm{pH}-$, ionic strength and temperature-sensitive hydrogel for insulin delivery. Polymer 51, 1687-1693 (2010).

38 Díez-Peña, E., Quijada-Garrido, I., Frutos, P. \& Barrales-Rienda, J. M. Thermal properties of cross-linked poly( $\mathrm{N}$-isopropylacrylamide) $[\mathrm{P}(\mathrm{N}-\mathrm{iPAAm})]$, poly(methacrylic acid) $[P(M A A)]$, their random copolymers [P(N-iPAAm-Co-MAA)], and sequential interpenetrating polymer networks (IPNs). Macromolecules 35, 2667-2675 (2002).

39 Lutz, J. F., Akdemir, Ö. \& Hoth, A. Point by point comparison of two thermosensitive polymers exhibiting a similar LCST: is the age of poly(NIPAM) over? J. Am. Chem. Soc. 128, 13046-13047 (2006).

40 Liras, M., García-García, J. M., Quijada-Garrido, I., Gallardo, A. \& París, R. Thermoresponsive allyl functionalized 2-(2-methoxyethoxy)ethyl methacrylate-based polymers as versatile precursors for smart polymer conjugates and conetworks. Macromolecules 44, 3739-3745 (2011).

Supplementary Information accompanies the paper on Polymer Journal website (http://www.nature.com/pj) 